\title{
Small Business Economics: An Entrepreneurship Journal Cherry-picking or frog-kissing? A theoretical analysis of how investors select entrepreneurial ventures in thin venture capital markets

\author{
--Manuscript Draft--
}

\begin{tabular}{|c|c|c|}
\hline Manuscript Number: & \multicolumn{2}{|l|}{ SBEJ-D-15-00006R2 } \\
\hline Full Title: & \multicolumn{2}{|c|}{$\begin{array}{l}\text { Cherry-picking or frog-kissing? A theoretical analysis of how investors select } \\
\text { entrepreneurial ventures in thin venture capital markets }\end{array}$} \\
\hline Article Type: & \multicolumn{2}{|l|}{ Original Research } \\
\hline Keywords: & \multicolumn{2}{|c|}{$\begin{array}{l}\text { High-Tech Entrepreneurship; Venture Capital; Sorting Mechanisms; Self-Selection } \\
\text { Out }\end{array}$} \\
\hline Corresponding Author: & \multicolumn{2}{|l|}{$\begin{array}{l}\text { Fabio Bertoni, Ph.D. } \\
\text { EMLYON Business School } \\
\text { Ecully, FRANCE }\end{array}$} \\
\hline \multicolumn{3}{|l|}{$\begin{array}{l}\text { Corresponding Author Secondary } \\
\text { Information: }\end{array}$} \\
\hline Corresponding Author's Institution: & \multicolumn{2}{|l|}{ EMLYON Business School } \\
\hline \multicolumn{3}{|l|}{$\begin{array}{l}\text { Corresponding Author's Secondary } \\
\text { Institution: }\end{array}$} \\
\hline First Author: & \multicolumn{2}{|l|}{ Fabio Bertoni, Ph.D. } \\
\hline \multicolumn{3}{|l|}{ First Author Secondary Information: } \\
\hline \multirow[t]{3}{*}{ Order of Authors: } & \multicolumn{2}{|l|}{ Fabio Bertoni, Ph.D. } \\
\hline & \multicolumn{2}{|l|}{ Diego D'Adda } \\
\hline & \multicolumn{2}{|l|}{ Luca Grilli } \\
\hline \multicolumn{3}{|c|}{ Order of Authors Secondary Information: } \\
\hline Funding Information: & $\begin{array}{l}\text { Seventh Framework Programme (BE) } \\
\text { (SSH-2007-1.2.3-G.A. 217485) }\end{array}$ & Not applicable \\
\hline Abstract: & \multicolumn{2}{|c|}{$\begin{array}{l}\text { We propose a formal model that analyzes which entrepreneurial ventures actively seek } \\
\text { and subsequently obtain venture capital (VC) financing in thin VC markets. The model } \\
\text { shows that in thin VC markets, (i) VC investors will invest in companies in need (frog- } \\
\text { kissing) rather than in best performers (cherry-picking), and (ii) the best performing } \\
\text { ventures will self-select out of the market for VC. These conclusions are in line with the } \\
\text { results from the literature, which note that in Europe many entrepreneurial firms do not } \\
\text { actively seek VC investment and that VC investors do not appear to possess the same } \\
\text { cherry-picking ability that they have in the US. }\end{array}$} \\
\hline
\end{tabular}




\title{
Cherry-Picking or Frog-Kissing? A Theoretical Analysis of how Investors Select Entrepreneurial Ventures in Thin Venture Capital Markets*
}

\author{
Fabio Bertoni ${ }^{a}$ \\ Diego D'Adda ${ }^{b}$ \\ Luca Grilli ${ }^{c}$
}

\begin{abstract}
We propose a formal model that analyzes which entrepreneurial ventures actively seek and subsequently obtain venture capital (VC) financing in thin VC markets. The model shows that in thin VC markets, (i) VC investors will invest in companies in need (frog-kissing) rather than in best performers (cherry-picking), and (ii) the best performing ventures will self-select out of the market for VC. These conclusions are in line with the results from the literature, which note that in Europe many entrepreneurial firms do not actively seek VC investment and that VC investors do not appear to possess the same cherry-picking ability that they have in the US.
\end{abstract}

Keywords: High-Tech Entrepreneurship, Venture Capital, Sorting Mechanisms, Self-Selection Out

JEL codes: L26, G24, M13

\footnotetext{
* We are grateful to two anonymous referees and to Silvio Vismara, the Associate Editor of the journal. We also thank, for their comments on early versions of this paper: Massimo G. Colombo, Ramy Elitzur, Terttu Luukkonen, Sophie Manigart, Marianna Mazzucato, José Martí Pellón, Tereza Tykvová, Elisa Ughetto, Mike Wright, and the participants to the final VICO conference (Stresa, Italy), the 37th EARIE Annual Conference (Istanbul, Turkey), the 2010 Zvi Griliches Research Summer Seminar in the Economics of Innovation (Barcelona, Spain) and the XXI AiIG annual meeting (L'Aquila, Italy). We acknowledge support from the Venture Fun project promoted by the EU PRIME Network of Excellence, and the VICO project funded under the European FP7 (SSH-2007-1.2.3-G.A. 217485).
}

a) Corresponding author. EMLYON Business School, ReCEntFin and Department of Economics, Finance and Control; 23 Avenue Guy de Collongue, 69134 Ecully - France. Email: bertoni@em-lyon.com. Phone: +33 (0)4 478337003.

b) Università Politecnica delle Marche - Dipartimento di Ingegneria dell'Informazione; Via Brecce Bianche, 60131 Ancona - Italy. Email: dadda@ dii.univpm.it. Phone: +39071 2204483.

c) Politecnico di Milano - Department of Management, Economics and Industrial Engineering; Via Lambruschini, 4B, 20156 Milan - Italy. Email: luca.grilli@ polimi.it. Phone: +39 0223993955. 


\title{
Cherry-Picking or Frog-Kissing? A Theoretical Analysis of how Investors Select Entrepreneurial Ventures in Thin Venture Capital Markets
}

\begin{abstract}
We propose a formal model that analyzes which entrepreneurial ventures actively seek and subsequently obtain venture capital (VC) financing in thin VC markets. The model shows that in thin VC markets, (i) VC investors will invest in companies in need (frog-kissing) rather than in best performers (cherry-picking), and (ii) the best performing ventures will self-select out of the market for VC. These conclusions are in line with the results from the literature, which note that in Europe many entrepreneurial firms do not actively seek $\mathrm{VC}$ investment and that $\mathrm{VC}$ investors do not appear to possess the same cherry-picking ability that they have in the US.
\end{abstract}

Keywords: High-Tech Entrepreneurship, Venture Capital, Sorting Mechanisms, Self-Selection Out JEL codes: L26, G24, M13 


\section{Introduction}

The literature on entrepreneurial finance is almost unanimous in identifying venture capital (VC) as the most appropriate financing mechanism for new high-tech entrepreneurial ventures, whereas debt financing is generally considered to be unable to address the specific needs of these nascent businesses in highly risky and uncertain markets. Banks usually lack both the competencies required to evaluate business ideas characterized by a high degree of technical complexity and the resources to effectively monitor these investments (Himmelberg and Petersen 1994, Carpenter and Petersen 2002). Collateralized loans are not a solution because the value of a young high-tech company is mostly in intangible assets, which normally cannot be used as collateral (Berger and Udell 1998).

VC firms, instead, are reputed to be able to overcome the inherent difficulties arising from debt financing and to alleviate the financial constraints of their portfolio companies (Bertoni et al. 2010, 2015b). Moreover, VC investors are generally found to create value in investee ventures by providing services (e.g., managerial support), performing a coaching function (Gorman and Sahlman 1989, Sapienza 1992, Lerner 1995, Kaplan and Strömberg 2003, 2004), signaling a company's quality to external stakeholders and, ultimately, providing these ventures with access to external resources and competencies that would otherwise be out of their reach (Stuart et al. 1999, Colombo et al. 2006, Hsu 2006, Lindsey 2008).

In principle, the superiority of $\mathrm{VC}$ over more traditional forms of external financing should provide VC investors with the ability to cherry-pick the best companies. Due to this sorting mechanism, the best companies should actively seek VC and should ultimately receive it. Sørensen (2007) reports evidence that this positive sorting characterizes the VC market in the United States (US), which is the largest and most developed VC market in the world (the US market accounted for $68 \%$ of global VC investments in 2013; see Ernst \& Young 2014).

The primary contribution of the present study is to empirically document and theoretically explain that the same type of sorting does not necessarily apply to thin VC markets such as those in most continental European countries, where the supply of VC is relatively scarce (EVCA 2010). The 
European market accounted for only $15 \%$ of global VC investments (Ernst \& Young 2014), which is

less than one-quarter the amount made in the US. Moreover, according to the European Venture Capital Association (2014), VC investments in Europe in 2013 were only $0.024 \%$ of GDP, which is less than one-seventh of the $0.17 \%$ observed in the US (OECD 2014). In this paper, we argue that the mechanisms that describe the matching process in a market as developed as the US do not necessarily apply to a thin market such as Europe.

Our theoretical argument relates to the large body of empirical literature that has tried to determine the extent to which the superior performance of VC-backed companies is attributable to a positive sorting effect or to a treatment effect (picking winners vs. building winners, in the words of Baum and Silverman 2004). More specifically, this empirical research stream focuses on investigating whether the success of investee firms is the result of value-added activities performed by VC investors or whether it is the natural consequence of the investors' ability to select good ventures (de Bettignies and Brander 2007). Overall, this empirical literature points to a much more economically relevant and statistically significant positive sorting effect in the US market wherein experienced VC investors select better (i.e., cherry-pick) targets, explaining much of the investees' subsequent performance (e.g., Sørensen 2007, Chemmanur et al. 2011). In contrast, this cherry-picking effect appears to be much less present in continental Europe, as documented by an increasing number of studies analyzing firm growth and productivity (see, for instance, the works by Engel 2002, Colombo and Grilli 2010, Bertoni et al. 2011, Croce et al. 2013).

A second contribution of our work is to show that the absence of a positive sorting mechanism can be linked to another piece of puzzling empirical evidence arising from the functioning of thin VC markets: the reluctance of companies to search for VC. The stylized fact that a non-negligible fraction of entrepreneurial ventures do not actively seek $\mathrm{VC}$ is hardly reconcilable with the evidence that, even in Europe, VC exerts on average a significant treatment effect on firm performance (e.g., Bank of England 2001, Engel and Keilbach 2007, Peneder 2010, Colombo and Grilli 2010; Bertoni et al. 2011). If VC is beneficial to entrepreneurial ventures, the question arises as to why entrepreneurial 
ventures appear to be so reluctant to actively seek it. Some qualitative studies suggest that the search

for VC investments by entrepreneurial ventures may bear high opportunity costs, particularly in less developed markets, and that this may result in self-selection out and consequently in the presence of non-allocated funds (dry powder) due to the shortage of available investing opportunities (Mason and Harrison 2001, Carpentier and Suret 2006).

In this paper, we show that VC market thinness reduces the incentive of potential investee companies to look for VC. More interestingly, company characteristics influence their tendency to be in the market for VC. Specifically, we show that when VC markets are thin, the matching process between candidates for VC investment and VC investors is better described as frog-kissing rather than cherry-picking. Our model shows that the best performing companies are the least likely to actively seek VC, and that VC is more likely to select a company for which its investment can have a large effect (i.e., select a frog that can be turned into a prince) rather than to a high-performing company (i.e., select the prince himself). Our model is consistent with the evidence that in Europe, high quality young high-tech companies self-select out of the market for $\mathrm{VC}$, and that no significant positive sorting mechanism by VC is detected.

We build a two-step matching model between VC investors and young high-tech companies which explicitly takes into account a sequential selection process. In the first step, entrepreneurial ventures decide whether to seek VC (i.e., to be in the market for VC) or not. In the second step, VC investors make their investment decision by selecting among the firms that, in the first step of the matching process, entered the market. Firms are characterized by two attributes: their potential growth and their available resources. We show that the decision by entrepreneurial ventures to enter the VC market depends positively on their potential growth and negatively on the amount of their available resources. The most interesting targets for $\mathrm{VC}$ investors are firms characterized by high growth potential but limited available resources. Companies that have high growth potential and abundant available resources, which are the best performing firms, are instead less interesting targets for VC. 
We label this preference of VC investors for resource-constrained companies as frog-kissing.

Other things being equal, $\mathrm{VC}$ investors prefer investing in a relatively inexpensive frog that can be turned into a prince rather than in the prince itself. The thinness of $\mathrm{VC}$ exacerbates this pattern, leaving in the market for $\mathrm{VC}$ only companies with poor performance and in desperate need of financing, pushing the best performing entrepreneurial ventures away from this source of financing.

The paper is structured as follows. In Section 2, we present the empirical evidence inspiring our work. In Section 3, we develop a formal matching model between demand and supply of VC and explain how frog-kissing arises. Section 4 introduces some extensions of the theoretical model. Section 5 concludes the paper.

\section{Empirical Evidence of Self-Selection Out of the Market for Venture Capital}

We present in this Section some figures describing the European context, which suggest the absence of any neat and unambiguous cherry-picking effect in the European VC market. We use information on 535 European high-tech entrepreneurial firms that replied to an on-line survey administered in 2010. The data are extracted from the VICO database, which includes detailed firm- and fund-level information for a large sample of $\mathrm{VC}$ and non-VC-backed firms operating in seven European countries: Belgium, Finland, France, Germany, Italy, Spain and the United Kingdom. ${ }^{1}$ All firms included in the sample comply with the gold-standard definition of new technology-based firm originally proposed by Arthur D. Little (1977): they are less than 25 years old, were independent at foundation, and operate in industries classified as high-tech sectors by the statistical classification of economic activities in the European Community (Eurostat, 2009). In the present work, we refer to a section of the VICO project on-line survey that was specifically focused on the financing process. Two focal questions were asked about the entrepreneurial venture: (a) was equity financing ever sought from investors other than company founders, their family members and friends? (b) Has the

\footnotetext{
1 The VICO dataset was built thanks to the joint effort of nine universities across Europe with the support of the 7th European Framework Program. For more details on the procedures used in the data gathering process and on all of the variables included in the dataset, see Bertoni and Martì (2011). For more information on the VICO project, please visit the dedicated website www.vicoproject.org.
} 
company ever entered into a formal negotiation for equity financing with investors other than

company founders, their family and friends, and what was the outcome of the negotiation?

A total of 535 usable questionnaires were received, corresponding to $178 \mathrm{VC}-$ backed firms and 357 non-VC-backed firms. In the following analysis, we use a time-invariant binary variable indicating whether a firm has ever sought VC financing. Out of 535 ventures, 253 (47.3\%) have at some point actively sought equity financing.

The self-selection out of the market for $\mathrm{VC}$ appears to be particularly relevant in countries where the VC market is relatively thin. In Table 1, we report the fraction of companies in VICO that confirmed having actively sought VC by country. We also report the placement of each country in a ranking compiled by the OECD and based on the ratio between VC investments and GDP (OECD, 2013). It is interesting to observe that the three countries for which the fraction of companies actively seeking VC is below average (Germany, Spain, and Italy) are characterized by the lowest OECD ranking (20, 23 and 29, respectively). This evidence lends support to the idea that in thin VC markets, companies are less likely to actively seek VC.

[Table 1 about here]

A second interesting piece of evidence comes from determining how many of the top-performing companies never actively sought VC. Specifically, we compare the fraction of top-performing companies that never sought $\mathrm{VC}$ with the fraction of top-performing companies that received $\mathrm{VC}$. The two groups are compared along several measures of performance: the logarithmic growth of sales and assets, return on equity (ROE), and return on assets (ROA).

We extract from the VICO dataset all firm-year observations of companies younger than 10 years that have never sought $\mathrm{VC}$ and those that eventually received $\mathrm{VC} .{ }^{2}$ We normalize the performance measures for industry, year and age and classify each observation according to the deciles of the

\footnotetext{
${ }^{2}$ To avoid contaminating our results with the treatment effect of $\mathrm{VC}$, we exclude from this analysis all the observations on the post-VC investment period for the VC-backed companies.
} 
distribution. ${ }^{3}$ For each of the two categories of companies, we compute the fraction of firms that

belong to the last decile of the distribution (i.e., the top performers). ${ }^{4}$ The results are illustrated in Figure 1. A $\chi^{2}$ test documents that there are differences in the distribution of these two categories of firms across the deciles of all performance measures. For sales growth $\chi^{2}(9)=32.48$, for assets growth $\chi^{2}(9)=31.14$, for $\operatorname{ROE} \chi^{2}(9)=26.79$ and for $\operatorname{ROA} \chi^{2}(9)=52.11$, all with $\mathrm{p}$-value $<1 \%$.

[Figure 1 about here]

Approximately $8 \%$ of the companies that never sought VC rank in the top decile of both growth measures, against between $14 \%$ and $16 \%$ of the companies that eventually received VC. This result suggests that, as one would expect, companies with the greatest growth look for and attract VC. However, the picture becomes more mixed when one considers performance measures such as profitability (ROE) and efficiency (ROA). On these measures, companies that never sought VC are overrepresented among the top-performers. For ROE, 11\% of companies that never sought VC are top performers, while the figure is less than $8 \%$ for companies that later received VC. The difference is even more pronounced for ROA: $12 \%$ of non-seeking companies are top performers against less than $6 \%$ of companies that later receive VC. In other words, more profitable and efficient companies exist among those that never sought VC than among those that eventually received it.

In sum, this evidence corroborates the view that self-selection out is relevant in thinner VC markets and that companies that ultimately become VC-backed in the European VC market are not necessarily better performing than those that stay out of the market for VC.

\footnotetext{
${ }^{3}$ The normalization is obtained by regressing the performance measure against industry, year and age fixed-effects and taking the residuals of the regression as the normalized performance measure.

${ }^{4}$ Similar evidence is obtained when we take into consideration the top quintile.
} 


\section{Matching between Investors and Young High-Tech Companies in Thin Venture Capital Markets}

In line with Eckhardt et al. (2006), we model matching between investors and young high-tech companies as a two-step process. In the first step, an entrepreneurial venture decides whether to actively seek VC (i.e., to be in the market for VC). In the second step, a VC investor selects the entrepreneurial venture from among those in the market. The VC investor takes the role of an informed intermediary (Chan 1983) and is able to overcome asymmetries in information and make available to its portfolio companies the resources they need. The key function of VC is thus twofold: VC investors, on the one hand, select the firms that will enter into their portfolio and, on the other, provide them with access to resources they would not otherwise obtain. These resources are not limited to financing but also embrace managerial experience and consultancy services intermediated by the VC investor alongside financial resources (Casamatta 2003).

To highlight this intermediation role of $\mathrm{VC}$ and its consequences for the matching process, we develop a simple framework in which companies differ along two dimensions: their growth potential and their endowment of resources. Companies may obtain additional resources on the market for resources, but at a higher marginal cost than for internal resources. The timing of the model is shown in Figure 2.

\section{[Figure 2 about here]}

At time $t=0, N$ entrepreneurial ventures are created. Each entrepreneurial venture is characterized by a certain growth potential $\left(a_{i}\right)$ and by a certain level of available resources $\left(\hat{b}_{i}\right)$. The parameter $\hat{b}_{i}$ captures any typology of resources (of a financial or a non-financial nature) founders possess or have access to without having to rely on the market for external resources. For the sake of simplicity, we will consider $\hat{b}_{i}$ to be a scalar, but the model could easily be generalized to the case of multiple types of resources. Each $\left(a_{i}, \hat{b}_{i}\right)$ vector completely characterizes entrepreneurial venture $i$; it is private information of the founders and is drawn independently from a joint probability density 
function $f(a, \hat{b})$ that is publicly known. Based on the vector of characteristics $\left(a_{i}, \hat{b}_{i}\right)$, the risk-neutral

founders must decide at $t=1$ whether they want to incur an entry cost $s$ to actively seek VC. At time $t=2$, a risk-neutral VC investor will invest in one company out of those that actively sought VC. Finally, at time $t=3$, entrepreneurs will determine the optimal amount of internal and external resources to use. As customary, we solve the game by backward induction. In Section 3.1, we describe the first-best and second-best solutions at time $t=3$ for a stand-alone (i.e., non-VC-backed) firm. In Section 3.2, we describe the effect of VC on a firm's decision at time $t=3$. In Section 3.3, we solve the problem for a VC investor at time $t=2$. Finally, we solve the decision by entrepreneurs at time $t=1$ in Section 3.4.

\subsection{The Choice of a Stand-Alone Firm at $t=3$}

The amount of resources that are used by the entrepreneurial team is $b \geq 0$, and eventually, the performance of a venture is the combination of its growth potential $(a)$ and the resources it uses $(b)$. The revenues generated by an entrepreneurial venture are given by $R(a, b)$. Some assumptions are made regarding the shape of the revenues function. First, $R_{a}>0$ and $R_{b}>0$, which means that higher revenues are generated by companies with better growth potential for any given level of resources and that abundant resources generate higher revenues than scarce resources for any given level of growth potential. We will assume $R(a, b)$ to be smooth and to satisfy customary concavity and Inada conditions to allow the existence and uniqueness of internal equilibria (namely $R_{a a}<0$, $\left.R_{b b}<0, \lim _{a \rightarrow+\infty} R_{a}=\lim _{b \rightarrow+\infty} R_{b}=0, \lim _{a \rightarrow 0} R_{a}=\lim _{b \rightarrow 0} R_{b}=+\infty\right)$.

Moreover, we assume $R(a, b)$ to be supermodular in $a$ and $b$, i.e., $R_{a b}>0$. This assumption means that as the amount of resources increases, the revenues increase faster in companies with high growth potential $\left(R_{b}\left(a^{\prime}, b\right)>R_{b}(a, b), \forall a^{\prime}>a\right)$ and that, symmetrically, if a company's growth potential increases, its revenues increase more when the resources available to the firm are more abundant $\left(R_{a}\left(a, b^{\prime}\right)>R_{a}(a, b), \forall b^{\prime}>b\right)$. In Section 4.1 we discuss the relevance of this assumption for our main results. 
In a first-best (FB) world in which firms face no information asymmetry, resources are available

at a constant marginal cost $\underline{c}$ such that, eventually, the value of a venture will be $\Pi_{\mathrm{FB}}(a, b)=$ $R(a, b)-\underline{c} b$. Knowing the marginal cost of resources and the growth potential of the company, entrepreneurs will choose an amount of resources for their business $\mathrm{b}_{\mathrm{FB}}(a)$ such that $R_{b}\left(a, b_{F B}(a)\right)=$ $\underline{c}$. By differentiating this first-order condition, we find that

$$
\mathrm{b}_{\mathrm{FB}}^{\prime}(a)=-\frac{R_{a b}}{R_{b b}}>0 .
$$

Thus, supermodularity ensures that $\mathrm{b}_{\mathrm{FB}}(a)$ is strictly increasing with $a$; therefore, at the first best, more resources will be used by the companies with better growth potential. Overall, the value of a firm at first best will be $\pi_{\mathrm{FB}}(a)=\Pi_{\mathrm{FB}}\left(a, b_{F B}(a)\right)$; differentiating $\pi_{\mathrm{FB}}(a)$ and using the envelope theorem, we find the following:

$$
\pi_{\mathrm{FB}}^{\prime}(a)=R_{a}\left(a, b_{F B}\right)>0 .
$$

Equation 2 shows that a firm's value grows together with its growth potential because, at first best, resources are always set to a level that is optimal conditional on $a$.

At second best, asymmetries in information make the acquisition of external resources more costly than the use of internal resources. Founders are naturally endowed with an amount $\hat{b}$ of resources at time $t=0$ that they can use when facing an opportunity cost $\underline{c}$. To obtain resources aside from those owned by its founders, the firm would need to look for them on the market for resources. As is customary, we assume the marginal cost of external resources to be higher than $\underline{c}$ and increasing monotonically with the amount of resources obtained (Fazzari et al. 1988). The marginal cost will thus be $c(b, \hat{b})=\underline{c}+\delta(b-\hat{b})$, where $\delta(x)$ is a continuous function that is equal to zero for $x \leq 0$ and is monotonically increasing for $x>0$, indicating the additional marginal cost of external resources over internal resources. The structure of the problem is illustrated in Figure 3.

[Figure 3 about here] 
The second-best (SB) profit function will now be given by $\Pi_{\mathrm{SB}}(a, b, \hat{b})=R(a, b)-$

$\int_{0}^{b} c(b) d b=\Pi_{\mathrm{FB}}(a, b)-\int_{0}^{b-\hat{b}} \delta(x) d x$. It should be stressed that assuming that the companies are endowed with internal resources means that they are not forced to look for external resources to conduct their business. When the amount of internal resources is small compared with $b_{F B}(a)$, a company might be willing to obtain expensive external resources to fill the gap.

It is easy to prove that access to external resources leads to underinvestment. The first-order condition at second-best is that $\mathrm{b}_{\mathrm{SB}}(a, \hat{b})$ should satisfy the following condition: $R_{b}\left(a, \mathrm{~b}_{\mathrm{SB}}(a, \hat{b})\right)=$ $\underline{c}+\delta\left(\mathrm{b}_{\mathrm{SB}}(a, \hat{b})-\hat{b}\right)$. When $\hat{b} \geq b_{F B}(a)$, the entrepreneurial team has sufficient internal resources to reach the first-best level without any need to look for external resources. When $\hat{b}<b_{F B}(a)$, the marginal return of the investment will need to compensate for the higher marginal cost of external resources, resulting in $\hat{b}<b_{S B}(a, \hat{b})<b_{F B}(a)$. By differentiating the first-order condition at secondbest and applying the envelope theorem, we find the following:

$$
\begin{aligned}
& \frac{\partial \mathrm{b}_{\mathrm{SB}}(a, \hat{b})}{\partial \mathrm{a}}=-\frac{R_{a b}}{R_{b b^{-}}-\delta^{\prime}} \leq \mathrm{b}_{\mathrm{FB}}^{\prime}(a) . \\
& \frac{\partial \mathrm{b}_{\mathrm{SB}}(a, \hat{b})}{\partial \hat{b}}=\frac{\delta^{\prime}}{R_{b b^{-}-\delta^{\prime}}} \leq 0 .
\end{aligned}
$$

Condition (3a) derives from the combination of supermodularity in the return function and the monotonic increase in the marginal cost of external resources. Condition (3a) shows that for any given amount of internal resources held by the entrepreneur, the higher is the growth potential $a$, the greater is the underinvestment (i.e., the distance between the first and second best level of $b$ ). Condition (3b) shows that underinvestment is greater, other things being equal, when internal resources $(\hat{b})$ are less.

Overall, the value of a firm at second best will be $\pi_{\mathrm{SB}}(a, \hat{b})=\Pi_{\mathrm{SB}}\left(a, \hat{b}_{i}, b_{S B}(a, \hat{b})\right)$; differentiating $\pi_{\mathrm{SB}}(a, \hat{b})$ and using the envelope theorem, we obtain the following:

$$
\begin{aligned}
& \frac{\partial \pi_{\mathrm{SB}}(a, \hat{b})}{\partial \mathrm{a}}=R_{a}\left(a, b_{S B}\right) \leq R_{a}\left(a, b_{F B}\right) . \\
& \frac{\partial \pi_{\mathrm{SB}}(a, \hat{b})}{\partial \hat{b}}=\delta \geq 0 .
\end{aligned}
$$


Condition (4a) shows that the marginal increase in a firm's value due to a marginal increase in

growth potential is less at second best than at first best. The inequality holds strictly when $\hat{b}<$ $b_{F B}(a)$. Condition (4b) shows that the smaller $\hat{b}$ is, the greater the spread between $\pi_{\mathrm{FB}}$ and $\pi_{\mathrm{SB}}$ becomes.

\subsection{The Role of Venture Capital}

We now introduce into the model the presence of VC. VC is portrayed as an investor that has the ability to overcome information asymmetries (Chan 1983) and that is characterized by valueenhancing abilities (e.g. managerial expertise) to the benefit of the investees (Casamatta 2003). When an entrepreneurial venture becomes VC-backed, it moves from a second-best world, in which internal resources and external resources are not perfect substitutes, to a first-best world, in which an infinite amount of resources are potentially available at a constant marginal cost $\underline{c}$. For the sake of simplicity, we make the assumption that only one $\mathrm{VC}$ investor exists and that it can only invest in one firm. $\mathrm{We}$ can then think of $N$ as the number of potential firms competing for one $\mathrm{VC}$ investment. The more developed the VC market is, the lower $N$ will be. Similarly to Sørensen (2007), here VC is assumed to be limited in the number of firms it can invest in rather than in the overall amount of resources it can provide. The rationale for this assumption is that the costs faced by VC to overcome asymmetries in information make diversification an unprofitable strategy (Kanniainen and Keuschnigg 2003). Moreover, assuming that $\mathrm{VC}$ is a monopoly greatly simplifies the analysis, which would otherwise require a more complex but probably less evocative framework (Elitzur and Gavious 2011). We extend the model by including a non-competing governmental VC investor in Section 4.2.

Consider now an entrepreneurial venture $i$ characterized by a vector $\left(a_{i}, \hat{b}_{i}\right)$. What is the potential benefit for this firm from obtaining VC? We can compute the increase in the firm's profits due to the presence of VC as $I_{i}=I\left(a_{i}, \hat{b}_{i}\right)=\pi_{\mathrm{FB}}-\pi_{\mathrm{SB}}$. If $\left(a_{i}, \hat{b}_{i}\right)$ such that $\hat{b}_{i} \geq b_{F B}\left(a_{i}\right)$, VC will not affect the venture's profits; the entrepreneurial team has sufficient resources to bring the company to firstbest, and no external resources will be needed. Accordingly, $\mathrm{VC}$ would not provide any benefit to the 
company. Conversely, for entrepreneurial ventures for which $\hat{b}_{i}<b_{F B}\left(a_{i}\right)$, the effect of VC will be

positive. The effect of VC may be conveniently rewritten as follows:

$$
\begin{gathered}
I_{i}=\Pi_{\mathrm{FB}}\left(a_{i}, b_{F B}\left(a_{i}\right)\right)-\Pi_{\mathrm{SB}}\left(a_{i}, \hat{b}_{i}, b_{S B}\left(a_{i}, \hat{b}_{i}\right)\right)= \\
\underbrace{\left(\Pi_{\mathrm{FB}}\left(a_{i}, b_{F B}\left(a_{i}\right)\right)-\Pi_{\mathrm{FB}}\left(a_{i}, b_{S B}\left(a_{i}, \hat{b}_{i}\right)\right)\right)}_{\text {Removal of underinvestment }}+\underbrace{\int_{0}^{b_{S B}\left(a_{i}, \hat{b}_{i}\right)-\hat{b}} \delta(x) d x}_{\begin{array}{c}
\text { Lower costs } \\
\text { of external resources }
\end{array}} .
\end{gathered}
$$

The first term in Equation (5) refers to the increase in value due to the removal of underinvestment. The second term refers to the lower cost of external resources in excess of $\hat{b}_{i}$. Because of Equations (4a) and (4b), it is straightforward to prove that when $\hat{b}_{i}<b_{F B}\left(a_{i}\right), I_{i}$ is increasing with growth potential $a_{i}$ and decreasing with internal resources $\hat{b}_{i}$ because both cause greater underinvestment and a higher cost of external resources.

Summarizing, the effect of $\mathrm{VC}$ is not the same for all entrepreneurial ventures. For some firms, namely those whose founders are endowed with a sufficient amount of resources, VC is useless. For firms that are forced to seek external resources, VC has an effect on performance that is greater when the company has greater growth potential and a scarcer endowment of internal resources.

\subsection{Venture Capital Selection at $t=2$}

Consider now that at $t=2, n \leq N$ entrepreneurial ventures have sought VC financing. These firms would receive a potential benefit from investment equal to $I_{i}$. Ventures are ranked over $I_{i}$ so that $I_{i} \geq$ $I_{i+1}$. Because $a_{i}$ is private information, $I_{i}$, which is a function of $\left(a_{i}, \hat{b}_{i}\right)$, is also the private information of the founders of venture $i$. The founders of venture $i$ do not know $I_{j}$ for $j \neq i$ but do know that other ventures' vectors of characteristics $(a, \hat{b})$ are independently drawn from a joint probability density function $f(a, \hat{b})$. In this simplified framework, the competition to obtain VC can then be modeled as an auction with private values in which each venture bids for VC by sharing with the VC investor a part of the value that VC adds to the venture, $I_{i}$. Ruling out the possibility of collusion by entrepreneurial ventures and referring to the risk-neutral assumption of the model, the revenue-equivalence theorem (Myerson 1981, Riley and Samuelson 1981) makes the auction process 
for VC irrelevant only if $n$ is known. In our case, $n$ is not known, but a similar result also holds when

only $N$ is known and entry into the contest is endogenous (Menezes and Monteiro 2000). Therefore, without any loss of generality, we can assume the auction to be second-price sealed-bid. In this setting, each entrepreneurial venture finds it optimal to bid its own $I_{i}$. In turn, if there are at least two companies in the market for $\mathrm{VC}$, the $\mathrm{VC}$ investor will choose the entrepreneurial venture for which it can produce the highest increase in value $I_{l}$, and the auction price it will pay will be equal to the value of the runner-up $I_{2}$. The VC investor will then internalize a fraction $I_{2} / I_{1}$ of its effect on firm 1 , and the rest will be captured by the entrepreneurial team. If the number of companies in the market for VC is less than 2, the profit for the VC investor will be zero.

It is worth stressing that the VC investor does not select ventures merely based upon their growth potential $a$ but rather selects based on the combination of growth potential, the extent of underinvestment due to limited internal resources, and the extra cost of the external resources necessary to maximize its effect. Consider, for instance, the case in which only 2 entrepreneurial ventures are in the market for $\mathrm{VC}$, firm $A$ and firm $B$. Assume that entrepreneurs in firm $B$ are endowed with lower resources $\left(\hat{b}_{A}>\hat{b}_{B}\right)$. Figure 4 illustrates how the choice of the VC investor is made in this case.

[Figure 4 about here]

The shaded region in the lower left portion of the plane is a region in which neither of the two firms has any advantage from obtaining VC $\left(I_{1}=I_{2}=0\right)$ and, as we will show in the next Section, in which neither of the two companies would be in the market for VC in the first place. The solid line represents the equation $I_{A}=I_{B}$. When $\left(a_{A}, a_{B}\right)$ lies in the portion of the plane above the solid line, firm $\mathrm{B}$ is preferred to firm $\mathrm{A}$. The dotted line in Figure 4 represents the equation $a_{A}=a_{B}$. The most interesting region is that between these two lines. In this region, firm B is preferred to firm A despite the fact that it has less growth potential $\left(a_{B}<a_{A}\right)$ and fewer internal resources. Firm B has a worse 
pre-investment performance than does firm A (because $a_{B}<a_{A}$ and $\hat{b}_{B}<\hat{b}_{A}$ ) and, if firm A becomes

VC-backed, it would have better post-investment performance than firm B (because $a_{B}<a_{A}$ ). A VC investor would prefer firm B to firm A because firm B has a greater improvement in performance if VC-backed, and a greater improvement in performance means a greater return for the VC investor. Firm A, instead, has a better stand-alone option and will be less disposed to share future profits with the VC investor. In other words, in a thin market in which the $\mathrm{VC}$ investor acts like a monopolist, frog-kissing may become more important than cherry-picking.

\subsection{A Firm's Decision to Actively Seek Venture Capital}

At time $t=1$, entrepreneurs must decide whether they want to actively seek VC or not. Let $g(I)$ be the a priori density distribution of $I$, that is, $I \sim g(I)$ and $G(i)=\operatorname{Pr}[I<i]$. Suppose that if an entrepreneurial team decides to actively seek VC, it will need to incur an entry cost $s$. Appendix A1 shows that in such an auction with private value and endogenous entry, a symmetric pure-strategy equilibrium exists in which each venture $j$ seeks VC and incurs entry cost $s$ if:

$$
I_{i}>\tilde{I}=\frac{s}{G\left(\tilde{I}^{N-1}\right.} .
$$

The threshold $\tilde{I}$ in Equation (6) increases monotonically with entry costs and with the number of potential competitors in the auction for VC, $N$. In other words, when entrepreneurs expect severe competition to obtain VC (i.e., when $N$ is large), they are more likely to self-select out of the market for VC. This self-selection out process could be so strong that the actual number of entrepreneurial ventures that decide to enter the market for VC may ultimately be only a very small portion of the firms that would potentially benefit from VC.

It is interesting to point out that high entry costs reduce the profitability of the VC investor, which is the following:

$$
\Pi_{V C}=\underbrace{E\left[I_{1}-I_{2}\right]}_{\begin{array}{c}
\text { Profitif } \\
n>1
\end{array}}(\underbrace{(1-\underbrace{G(\tilde{I})^{N}}_{\text {Prob. } n}-\underbrace{G(\tilde{I})^{N-1}\left(1-G(\tilde{I})^{N}\right)}_{\text {Prob }})}_{\begin{array}{c}
\text { Probability that } \\
n>1
\end{array}} .
$$


Where the first term is the expected profit if $n>1$ (which only depends on $N$ and on the

distributional properties of $I$ ), and the second term is the probability that the number of companies on the market or VC is 2 or greater. It is easy to show that as $s$ increases the profitability of $\mathrm{VC}$ decreases because of two reasons: the increase in the probability that no company will be on the market for VC; and the increase in the probability that only one company will be in the market for $\mathrm{VC}$, exercising monopsonistic power. In summary, entry costs harm VC profitability because they decrease competition to get VC.

As shown in section 3.2, $I$ is increasing with growth potential $a$ and decreasing with available resources $\hat{b}$. These relationships mean that as $N$ increases, only ventures with high growth potential (high $a$ ) and very limited internal resources (low $\hat{b}$ ) will enter the market for VC. These are the entrepreneurial ventures that are the most exposed to underinvestment and not the best performing companies. In thin markets, we would thus expect the best performing companies to self-select out of the market. The most profitable and productive companies will not actively seek VC, whereas the less profitable companies with high growth potential will be the most likely to seek and subsequently obtain VC. This prediction is entirely in line with the evidence shown in Figure 1.

\section{Extensions and Generalization of the Model}

In this Section, we introduce some extensions to the model presented in Section 3. In Section 4.1 we will discuss how the predictions of the model would change if we assumed submodularity instead of supermodularity between resources and growth potential. In Section 4.2, we will elaborate on how the presence of a governmental $\mathrm{VC}$ could affect the matching process.

\subsection{Relaxing the Supermodularity Assumption}

In Section 3, we have assumed that $\mathrm{R}(\mathrm{a}, \mathrm{b})$ is supermodular in $a$ and $b$. This assumption means that resources will be more productive (i.e., they will generate higher revenue) when combined with an investment opportunity with a better growth potential. Put differently, resources and growth potential are complementary inputs in the production function. In this section we study how the predictions of 
the model would be affected if, instead, $\mathrm{R}(\mathrm{a}, \mathrm{b})$ was submodular in $a$ and $b$, i.e. if $R_{a b}<0$.

Specifically, we will show that some predictions of the model are reversed, while others are confirmed.

First, because of submodularity the amount of resources used at first-best by the company in equation (1) is now decreasing in $a$, which means that companies with better growth opportunities will need fewer resources to achieve them. Similarly, in equation (3a) the amount of resources used at second-best is also decreasing with $a$, which means that underinvestment occurs now for low (not high) levels of $a$. This result means that, under submodularity, the companies with the best growth opportunities are not the ones that are financially constrained, which are instead those that have the poorest growth opportunities.

However, equations (3b) and (4b) are unchanged in case of submodularity: small amounts of available resources $(\hat{b})$ result, at second-best, in underinvestment and lower profits. Similarly, Equation (5) is unchanged: the impact of $\mathrm{VC}$ is the combination of two effects: the removal of underinvestment and the lower cost for the acquisition of the additional financial resources. However, due to submodularity the companies that will enjoy the greatest impact from $\mathrm{VC}$ are those with a low level of available resources $(\hat{b})$ and low (not high) growth opportunities (a). Accordingly, in Figure 4 the decision criterion of $\mathrm{VC}$ would be reversed: B would be preferred over A below (not above) the solid line $\left(I_{A}=I_{B}\right)$.

Finally, all the results in Section 3.4 are confirmed: entry costs and the number of potential competitors will increase the threshold for companies to be in the market for VC. And, similarly, the expected profits for $\mathrm{VC}$ will decrease with entry costs because of lower competition among investable companies.

In summary, some of the predictions of the model are independent of the assumption about the modularity of the revenue function: the companies that are in the market for $\mathrm{VC}$ will not be the best 
performers, ${ }^{5}$ an increase in entry costs will translate in a reduced deal flow and profits for the VC.

However, under submodularity the companies that will be in the market for VC will be characterized by the worst (not best) growth opportunities, which is the opposite of what predicted under supermodularity.

Overall, the predictions obtained by the model under supermodularity of resources in the revenue function are more in line with both our intuition of the functioning of the VC market and with the comparative analysis illustrated in Section 2.

\subsection{The Effect of Governmental VC on the Matching Process}

When we introduced VC in Section 3.2, we implicitly described it as an independent VC (IVC). An IVC is characterized by purely financial investment objectives achieved through the separation between the ultimate investors and the investment managers (Sahlman 1990). IVC is the dominant type of VC in the US and in Europe (Bertoni et al. 2015a). However, VC markets are, especially in Europe, also characterized by the presence of captive VC investors (Bottazzi and Da Rin 2002). In this section, we extend the model presented in Section 3 to illustrate how the matching between investors and investees may be influenced by the presence of a specific type of captive VC: governmental VC (GVC) (for a comprehensive review of GVC for innovative young firms see Colombo et al. 2014). The choice of introducing GVC in the model has two main motivations. First, most GVCs have been created with the explicit objective of supporting innovative companies in regions in which the VC market is thin (Hood 2000, Bertoni and Tykvova 2015). As a result, it is natural to wonder how a GVC would affect the matching process in a thin VC market described in Section 3. Second, GVC is the VC investor that exhibits the most strikingly different investment characteristics from IVC (Brander et al. 2008, 2015). GVC appears to be specialized in companies that are characterized by high investment risk (Cumming and Johan 2009, Buzzacchi et al. 2013, Bertoni et al. 2015a) and rarely result in a profitable exit (Cumming et al. 2014). In addition, the impact of GVC on firms

\footnotetext{
${ }^{5}$ The effect is even stronger under submodularity because both $a$ and $\hat{b}$ are below-average for companies in the market for $\mathrm{VC}$.
} 
performance is significantly smaller than IVC's in terms of productivity, growth and patenting (Bertoni and Tykvova 2015, Grilli and Murtinu 2014, 2015).

In our model, a greater number of IVCs (i.e., a lower $N$ ) will make the market less thin, increase the deal flow and bring better performing companies on the market for VC. A similar effect might be obtained, arguably, if captive VCs similar to IVC were present. However, it is unclear whether the same effect may be obtained by introducing in the $\mathrm{VC}$ market a GVC, which is shown by the literature to be less effective than IVC in terms of impact and selection.

We explore the impact of GVC on the matching process described in Section 3 by assuming that companies in the market for $\mathrm{VC}$, which did not get IVC, will have a probability $\pi$ of obtaining GVC. On the one hand, this assumption means that GVC is non-competitive to IVC: only companies that did not get IVC have a probability of obtaining GVC. On the other hand, the fact that $\pi$ does not depend on the characteristics of the company $\left(a_{i}, \hat{b}_{i}\right)$ means that we are assuming that GVC does not have any screening ability. Assuming that GVC has a non-competitive nature and no screening ability, greatly simplifies the analysis and captures the idiosyncratic difference between GVC and IVC.

Similarly, we assume that the impact of GVC is less than IVC's. Specifically, the value enhancement from GVC will be a fraction $\varphi<1$ of the impact $I_{i}$ which the company would obtain from IVC. In Appendix A.2 we prove the following proposition:

Proposition 1: In presence of a non-competitive GVC with no screening capabilities and a fraction $\varphi$ of IVC's value-enhancement ability, a firm $j$ will be on the market for VC if $I_{j}>\tilde{I}_{G V C}$, where $\tilde{I}_{G V C}$ is such that:

$$
\tilde{I}_{G V C}\left(G\left(\tilde{I}_{G V C}\right)^{N-1}+\pi \varphi\left(1-G\left(\tilde{I}_{G V C}\right)^{N-1}\right)\right)=s
$$

$\tilde{I}_{G V C}$ is less than the impact threshold $\tilde{I}$ in absence of GVC. The reduction in the impact threshold determines an increase in the expected profit of IVC. 
Proposition 1 shows that GVC can, indeed, be beneficial in a thin VC market even if it lacks

any screening ability and it is less effective than an IVC in enhancing the value of the investee company. The benefit of GVC comes, in our model, in the form of an increased propensity of potential VC targets to be on the market for VC. The threshold beyond which a company decides to actively seek VC goes from $\tilde{I}$ to $\tilde{I}_{G V C}<\tilde{I}$. In other words, by giving a second prize to companies that are on the market for $\mathrm{VC}, \mathrm{GVC}$ obtains a result that is the equivalent of a reduction in the entry cost $(s)$.

A less intuitive positive effect of GVC is the increase in the expected profit for IVC. GVC increases the deal flow which increases the competition to get IVC. In turn, increased competition causes an increase in expected profits for IVC. It is important to highlight that this result is valid under the assumption that GVC does not compete with IVC, because the presence of GVC only benefits companies that do not obtain IVC. Put differently, companies cannot use GVC to obtain a higher valuation from IVC. Studying competition between the two investors is beyond the scope of this paper, yet it is interesting to know that, without such competition, in a thin market a GVC may actually increase the expected profit for IVC investors through the increased deal flow, which is a mechanism that has not received sufficient attention in the literature.

\section{Conclusions}

This paper offers a formal explanation of why under some specific conditions, the best performing companies may self-select out of the VC market. We develop a two-step matching model between a VC investor and $N$ heterogeneous entrepreneurial ventures. Our analysis shows that entrepreneurial ventures willing to be in the market for $\mathrm{VC}$ when such a market is thin are not necessarily the best performers but instead represent firms with high growth potential and low resources. In this context, the intermediation role of $\mathrm{VC}$ is better described as frog-kissing (i.e., select the frog that can be turned into a prince) than as cherry-picking (i.e., select the prince). 
The primary contribution of the paper is that it provides a solid theoretical basis for a consolidated

body of empirical studies that highlight how the treatment effect of $\mathrm{VC}$ investments on the performance of portfolio ventures is much more prominent in relatively less-developed VC markets such as most countries in continental Europe. Conversely, less-developed VC markets appear to be characterized by less relevant positive sorting (e.g., Engel 2002, Colombo and Grilli 2010, Bertoni et al. 2011, Croce et al. 2013) than has been observed in the US (Sørensen 2007 and Chemmanur et al. 2011). Our theoretical result strengthens the breadth and robustness of the empirical evidence produced on this topic, but it also offers new and interesting insights. In particular, we highlight how the intrinsic costs incurred by young high-tech companies to enter a thin VC market might be an important factor explaining the frog-kissing market outcome. Thus, to the extent that a) the absence of positive sorting mechanisms in the market is detrimental to social welfare and b) high entry costs incurred by entrepreneurial ventures in a thin $\mathrm{VC}$ market are not totally exogenous to policy action, our theoretical effort individuates the lowering of entry barriers to the thin VC market as an important channel for policymaking. Accordingly, any policy mechanisms that, particularly at the local level, are able to "signal" best performing young high-tech companies and thus automatically lower their search costs could prove to be extremely beneficial for social welfare. The "halo" and certification function of direct public intervention has been found to hold for entrepreneurial ventures operating in different institutional contexts, from the US (e.g., Lerner 1999) to Europe (e.g., Revest and Sapio 2012). Therefore, our results suggest that relatively soft inexpensive instruments, such as start-up competitions and contests, prizes, selected investment brokerage and other bridging activities, could prove to be as effective as other more structured and expensive measures (e.g., grants and selective subsidies; see Colombo et al. 2013) by increasing firms' networking capabilities and/or increasing their visibility and appeal to third parties (Nishimura and Okamuro 2011).

Finally, our model also illustrates a mechanism through which GVC may benefit a thin VC market. Specifically, we show that a non-competitive GVC will increase the deal flow and the expected profits of IVC even if it is less effective than IVC in its treatment effect and not able to 
screen the companies based on their characteristics. This result suggests that to the extent to which it does not compete with IVC investors on the same deals, a GVC may increase the profitability of VC investments in a region, possibly attracting additional investors and triggering the virtuous cycle of VC market development. 


\section{References}

Bank of England, 2001. Financing of technology-based small firms. Second Report, Domestic Finance Division, Bank of England.

Baum, J.A.C., Silverman, B.S., 2004. Picking winners or building them? Alliance, intellectual, and human capital as selection criteria in venture financing and performance of biotechnology startups. Journal of Business Venturing 19, 411-436.

Berger, A.N., Udell, G.F., 1998. The economics of small business finance: The roles of private equity and debt markets in the financial growth cycle. Journal of Banking and Finance 22, 613-673.

Bertoni, F., Colombo, M.G., Croce, A., 2010. The effect of venture capital financing on the sensitivity to cash flow of firm's investments. European Financial Management 16(4), 528-551.

Bertoni, F., Colombo, M.G., Grilli, L., 2011. Venture capital financing and the growth of high-tech start-ups: disentangling treatment from selection effects. Research Policy 40, 1028-1043.

Bertoni, F., Colombo, M.G., Quas, A., 2015a. The patterns of venture capital investment in Europe. Small Business Economics 45(3), 543-560.

Bertoni, F., Croce, A., Guerini, M., 2015b. Venture capital and the investment curve of young hightech companies. Journal of Corporate Finance 35, 159-176.

Bertoni, F., Martí, J., 2011. Financing Entrepreneurial Ventures in Europe: The Vico Dataset (SSRN Scholarly Paper No. ID 1904297). Social Science Research Network, Rochester, NY.

Bertoni, F., Tykvová, T. (2015). Does governmental venture capital spur invention and innovation? Evidence from young European biotech companies. Research Policy 44, 925-935.

Bottazzi, L., Da Rin, M., 2002. Venture capital in Europe and the financing of innovative companies. Economic Policy 17(34), 229-270.

Brander, J.A., Du, Q., Hellmann, T., 2015. The effects of government-sponsored venture capital: International evidence. Review of Finance 19(2), 571-618.

Brander, J.A., Egan, E., Hellmann, T., 2008. Government sponsored versus private venture capital: Canadian evidence. In J. Lerner, A. Schoar (Eds.), International differences in entrepreneurship, Chapter 10. Chicago: University of Chicago Press.

Buzzacchi, L., Scellato, G., Ughetto, E., 2013. The investment strategies of publicly sponsored venture capital funds. Journal of Banking and Finance 37(3), 707-716. 
Carpenter, R.E., Petersen, B.C., 2002. Capital market imperfections, high-tech investment, and new equity financing. Economic Journal 112, F54-F72.

Carpentier, C., Suret, J.M., 2006. Some evidence of the external financing costs of new technology based firms in Canada. Venture Capital 8, 227-252.

Casamatta, C., 2003. Financing and advising: optimal financial contracts with venture capitalists. Journal of Finance 58, 2059-2085.

Chan, Y.S., 1983. On the positive role of financial intermediation in allocation of venture capital in market with imperfect information. Journal of Finance 35, 1543-1568.

Chemmanur, T. J., Krishnan, K., Nandy, D. K., 2011. How does venture capital financing improve efficiency in private firms? A look beneath the surface. Review of Financial Studies 24, 4037-4090.

Colombo, M.G., Cumming, D.J., Vismara, S., 2014. Governmental venture capital for innovative young firms. Journal of Technology Transfer, forthcoming, first on line: 06 December 2014, DOI 10.1007/s10961-014-9380-9.

Colombo, M.G., Giannangeli, S., Grilli, L., 2013. Public subsidies and the employment growth of high-tech start-ups: assessing the impact of selective and automatic support schemes. Industrial and Corporate Change 22, 1273-1314.

Colombo, M.G., Grilli, L., 2010. On growth drivers of high-tech start-ups: the role of founders' human capital and venture capital. Journal of Business Venturing 25, 610-626.

Colombo, M.G., Grilli, L., Piva, E., 2006. In search of complementary assets: the determinants of alliance formation of high-tech start-ups. Research Policy 35, 1166-1199.

Croce, A., Martí, J., Murtinu, S., 2013. The impact of venture capital on the productivity growth of European entrepreneurial firms: "screening" or "value added" effect? Journal of Business Venturing, $28,489-510$.

Cumming, D. J., Grilli, L., Murtinu, S., 2014. Governmental and independent venture capital investments in Europe: A firm-level performance analysis. Journal of Corporate Finance, forthcoming, first on line: 24 October 2014, DOI 10.1016/j.jcorpfin.2014.10.016.

Cumming, D.J., Johan, S., 2009. Pre-seed government venture capital funds. Journal of International Entrepreneurship, 7, 26-56. 
de Bettignies, J-E., Brander, J.A., 2007. Financing entrepreneurship: bank finance versus venture capital. Journal of Business Venturing 22, 808-832.

Eckhardt, J.T., Shane, S., Delmar., F., 2006. Multistage selection and the financing of new ventures. Management Science 52, 220-232.

Elitzur, R., Gavious, A., 2011. Selection of entrepreneurs in the venture capital industry: an asymptotic analysis. European Journal of Operational Research 215, 705-712.

Engel, D., 2002. The Impact of Venture Capital on Firm Growth: an Empirical Investigation. Discussion Paper No. 02-02, Centre for European Economic Research (ZEW), Mannheim.

Engel, D., Keilbach, M., 2007. Firm level implication of early stage venture capital investment: an empirical investigation. Journal of Empirical Finance 14, 150-167.

Ernst \& Young, 2014. Adapting and Evolving, Global Venture Capital Insights and Trends 2014 Report.

European Venture Capital Association (EVCA), 2010. Closing Gaps and Moving Up a Gear: the Next Stage of Venture Capital's Evolution in Europe. EVCA Venture Capital White Paper.

European Venture Capital Association (EVCA), 2014. 2013 European Private Equity Activity: Statistics on Fundraising, Investments \& Divestments. Annual Yearbook.

Eurostat, 2009. Eurostat Indicators of High-tech Industry and Knowledge - Intensive Services. Annex 3 - High-tech Aggregation by NACE Rev. 2.

Fazzari, S., Hubbard, R.G., Petersen, B.C., 1988. Financing constraints and corporate investment. Brookings Papers on Economic Activity 1, 141-195.

Gorman, M., Sahlman, W. A., 1989. What do venture capitalists do? Journal of Business Venturing 4, $231-248$

Grilli, L., Murtinu, S., 2014. Government, venture capital and the growth of European high-tech entrepreneurial firms. Research Policy 43, 1523-1543.

Grilli, L., Murtinu, S., 2015. New technology-based firms in Europe: market penetration, public venture capital, and timing of investment. Industrial and Corporate Change 24, 1109-1148.

Himmelberg, C.P., Petersen, B.C., 1994. R\&D and internal finance: a panel study of small firms in high-tech industries. Review of Economics and Statistics 76, 38-51. 
Hood, N. (2000). Public venture capital and economic development: The Scottish experience. Venture Capital: an International Review 2(4), 313-341.

Hsu, D. H., 2006. Venture capitalists and cooperative start-up commercialization strategy. Management Science 52, 204-219.

Kaplan, S. N., Strömberg, P., 2003. Financial contracting theory meets the real world: an Empirical analysis of venture capital contracts. Review of Economic Studies 70, 281-315.

Kaplan, S. N., Strömberg, P., 2004. Characteristics, contracts, and actions: evidence from venture capitalist analyses. Journal of Finance 59, 2177-2210.

Kanniainen, V., Keuschnigg C., 2003. The optimal portfolio of start-up firms in venture capital finance. Journal of Corporate Finance 9, 521-534.

Lerner, J., 1995. Venture capitalists and the oversight of private firms. Journal of Finance 50, 301318.

Lerner, J., 1999. The government as venture capitalist: the long-run impact of the SBIR program. Journal of Business 72, 285-318.

Lindsey, L., 2008. Blurring firm boundaries: the role of venture capital in strategic alliances. Journal of Finance 63, 1137-1168.

Mason, C.M., Harrison, R.T., 2001. 'Investment readiness': a critique of government proposals to increase the demand for venture capital. Regional Studies 35, 663-668.

Manigart, S., Van Hyfte, M., 1999. Post-investment evolution of venture backed companies. In: Reynolds, P., Bygrave, W., Manigart, S., Mason, C., Meyer, G., Sapienza, H.J., Shaver, K., (Eds.), Frontiers of Entrepreneurship Research. Babson College: Wellesley, MA.

Menezes, F.M, Monteiro, P., 2000. Auctions with endogenous participation. Review of Economic Design 5, 71-89.

Myerson, R.B., 1981. Optimal auction design. Mathematics of Operations Research 6, 58-73.

Nishimura, J., Okamuro, H., 2011. Subsidy and networking: the effects of direct and indirect support programs of the cluster policy. Research Policy 40, 714-727.

OECD, 2013. Entrepreneurship at a Glance: Venture Capital and the Crisis. OECD Annual Report. OECD, 2014. Entrepreneurship at a Glance: Venture Capital and the Crisis. OECD Annual Report. 
Peneder, M., 2010. The impact of venture capital on innovation behaviour and firm growth. Venture Capital 12, 83-107.

Revest, V., Sapio, A., 2012. Financing technology-based small firms in Europe: what do we know? Small Business Economics 39, 179-205.

Riley, J.G., Samuelson, W.F., 1981. Optimal auctions. American Economic Review 71, 381-392.

Sahlman, W.A., 1990. The structure and governance of venture-capital organizations. Journal of Financial Economics 27(2), 473-521.

Sapienza, H. J., 1992. When do venture capitalists add value? Journal of Business Venturing 7, 9-27.

Sørensen, M., 2007. How smart is smart money? A two-sided matching model of venture capital. Journal of Finance 62, 2725-2762.

Stuart, T. E., Hoang, H., Hybels, R. C., 1999. Interorganizational endorsements and the performance of entrepreneurial ventures. Administrative Science Quarterly 44, 315-349. 


\section{Tables and Figures}

1

2

Table 1: Country Breakdown of European High-Tech Entrepreneurial Ventures

\begin{tabular}{lccccccc}
\hline \hline & $\begin{array}{c}\text { OECD } \\
\text { ranking for } \\
\text { VC } \\
\text { Country }\end{array}$ & \multicolumn{2}{l}{ Not actively seeking VC } & Actively seeking VC & \multicolumn{2}{c}{ Total } \\
\hline Finland & 8 & 38 & 51.35 & 36 & 48.65 & 74 & 100 \\
United Kingdom & 9 & 29 & 41.43 & 41 & 58.57 & 70 & 100 \\
France & 15 & 38 & 42.70 & 51 & 57.30 & 89 & 100 \\
Belgium & 18 & 20 & 38.46 & 32 & 61.54 & 52 & 100 \\
Germany & 20 & 17 & 56.67 & 13 & 43.33 & 30 & 100 \\
Spain & 23 & 74 & 60.16 & 49 & 39.84 & 123 & 100 \\
Italy & 29 & 66 & 68.04 & 31 & 31.96 & 97 & 100 \\
Total & & 282 & 52.71 & 253 & 47.29 & 535 & 100 \\
\hline
\end{tabular}

Source: VICO dataset and OECD (2013)

Figure 1: Fraction of Companies in the Top Decile of Different Normalized Performance Measures

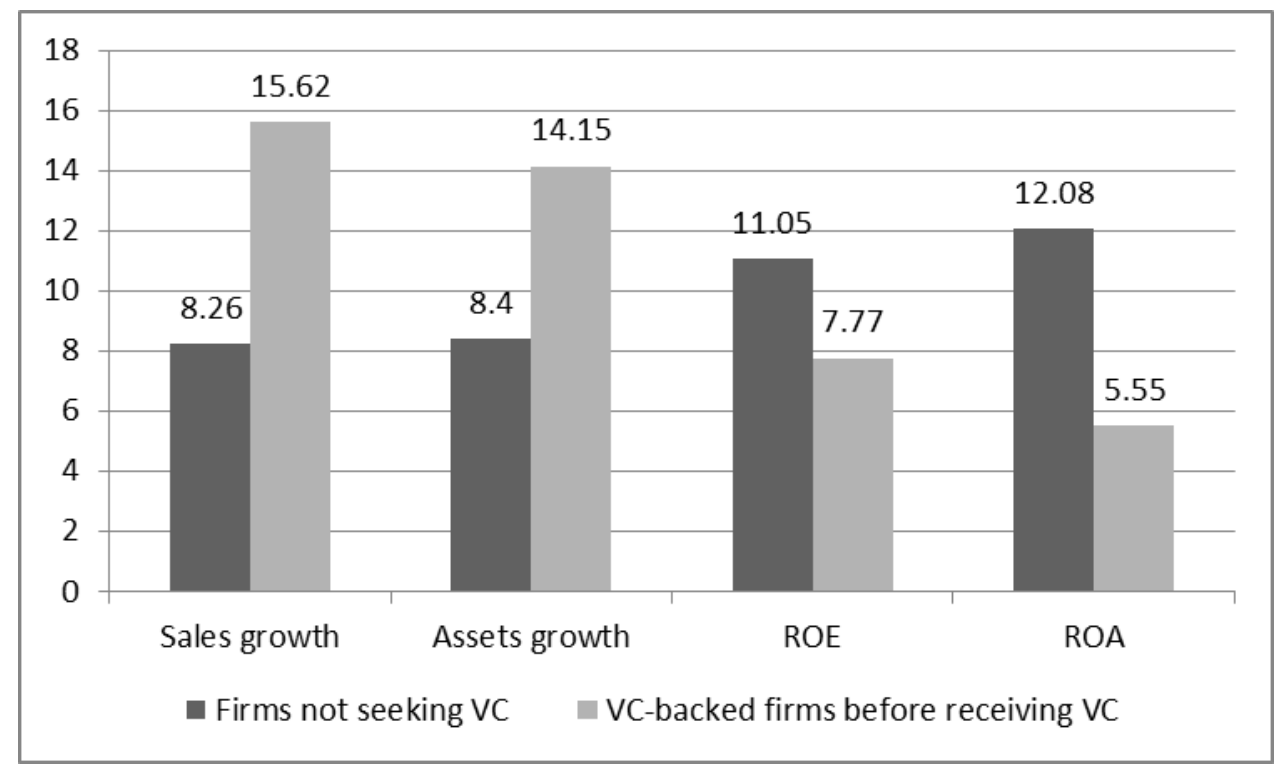

Legend. Each bar represents the fraction of companies in the relevant group in the top decile of the respective normalized performance measure. We consider two groups of companies: those that never actively sought $\mathrm{VC}$ and those that eventually become VC-backed. For VC-backed firms we only consider the observations-year before obtaining venture capital. Each performance measure is normalized for year, sector and age fixed-effects. 
Figure 2: Timeline of the Model

1

2

Figure 3: Marginal Revenue and Cost of Resources

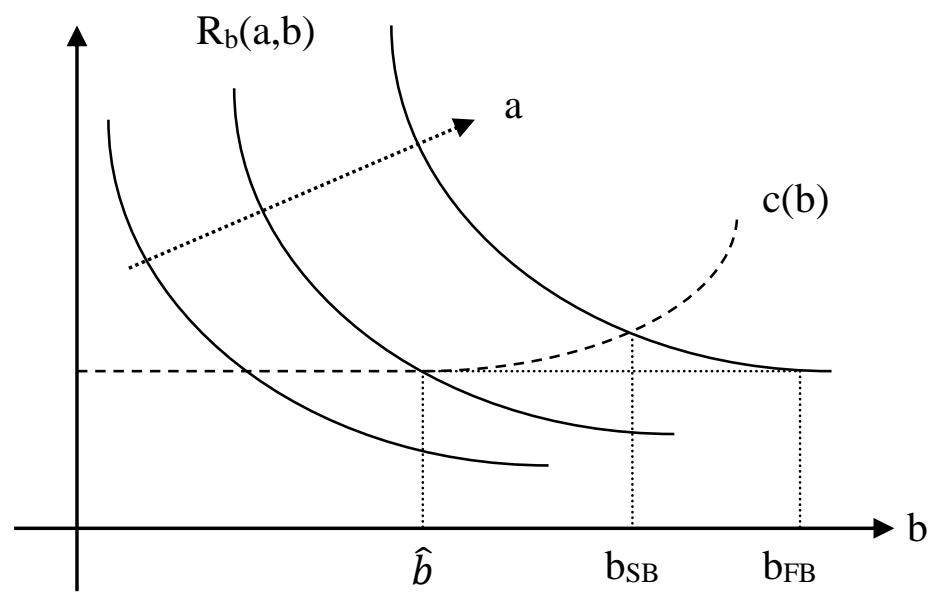

Figure 4: VC Selection in a 2-Player Game when $\hat{b}_{A}>\hat{b}_{B}$

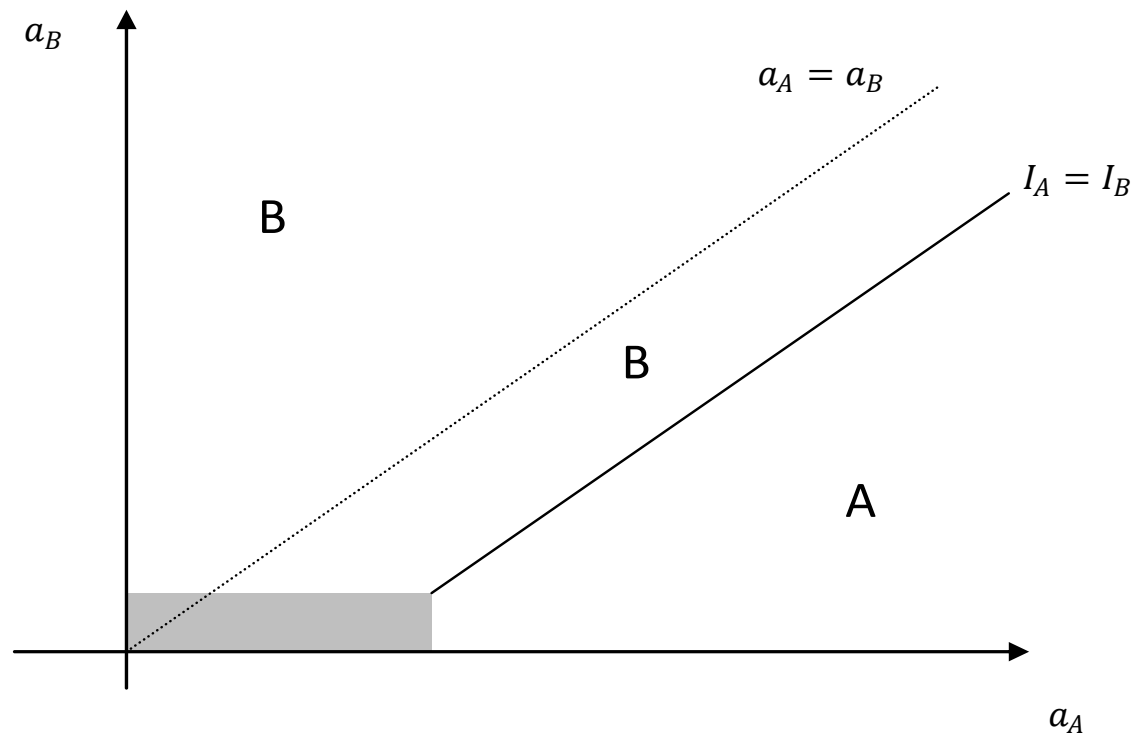




\section{Appendix}

\section{A.1 Proof of Equation (6)}

Equation (6) follows directly from the theory of auctions with endogenous participation (Menezes and Monteiro 2000). We provide here a proof adapted to our particular framework. If a venture enters into the market for $\mathrm{VC}$, it enters a competition in which, at time $t=2$, it will only gain if it gets financed. The selection process of $\mathrm{VC}$, which has been discussed in Section 3.3, is known by the entrepreneurs at time $t=1$. Let $I_{\max }$ be the maximum impact that $\mathrm{VC}$ has on all other $N-1$ ventures that potentially compete for VC. The cumulative distribution of $I_{\max }$ is the following: $H(i)=\operatorname{Pr}\left[I_{\max }<i\right]=$ $G(i)^{N-1}$. The probability density function of $I_{\max }$ is thus the following: $h(i)=(N-1) G(i)^{N-2} g(i)$. The entrepreneur knows that $\tilde{I}$ is the threshold for participation in the market for VC for all players. For $I_{j}>\tilde{I}$, the expected gain $V\left(I_{j}\right)$ from being in the market for $\mathrm{VC}$ for the entrepreneur is the following:

$$
V\left(I_{j}\right)=\underbrace{\int_{0}^{\tilde{I}} I_{j} h(i) d i}_{\begin{array}{c}
\text { Expected gain if } \\
I_{\text {max }}<\tilde{I}
\end{array}}+\underbrace{\int_{\tilde{I}}^{I_{j}}\left(I_{j}-i\right) h(i) d i}_{\begin{array}{c}
\text { Expected gain if } \\
I_{\text {max }}>\tilde{I}
\end{array}} .
$$

The first term of equation (A1) derives from the fact that if $I_{\max }<\tilde{I}$, no other firm will be in the market for $\mathrm{VC}$ and entrepreneurs will internalize all the value $I_{j}$. The second term in (A1) derives from the fact that if $I_{\max }>\tilde{I}$, the entrepreneur will have to share some of the value-creation with the $\mathrm{VC}$ because of competition in the auction. If $I_{\max }>I_{j}$, the venture will not be financed by VC and will not receive any benefit from being in the market for VC. Both terms of $V\left(I_{j}\right)$ are strictly increasing in $I_{j}$. The equilibrium level of $\tilde{I}$ is thus unique and such that $V(\tilde{I})=s$. Integrating the first term of (A1) (the other being null) leads to the following:

$V(\tilde{I})=\int_{0}^{\tilde{I}} \tilde{I} h(i) d i=\tilde{I}(N-1) \int_{0}^{\tilde{I}} G(i)^{N-1} g(i) d i=\tilde{I} G(\tilde{I})^{N-1}$

By equating equation (A2) to $s$ we obtain the following:

$$
\tilde{I}=\frac{s}{G(\tilde{I})^{N-1}} .
$$

Which proves Equation (6). 


\section{A.2 Proof of Proposition 1}

For this proof we use the same notation as in Appendix A.1. If a venture $j$ enters into the market for $\mathrm{VC}$, it enters a competition in which, at time $t=2$, it will gain from IVC if $I_{j}>I_{\max }$ or, else, will gain from GVC with a probability $\pi$. Let $\tilde{I}_{G V C}$ be the threshold impact to be on the market for VC. For $I_{j}>$ $\tilde{I}_{G V C}$, the expected gain from being in the market for VC for the entrepreneur is the following:

$V_{G V C}\left(I_{j}\right)=\underbrace{\int_{0}^{\tilde{I}_{G V C}} I_{j} h(i) d i+\int_{\tilde{I}_{G V C}}^{I_{j}}\left(I_{j}-i\right) h(i) d i}_{\text {Expected gain from IVC }}+\underbrace{\pi \int_{I_{j}}^{+\infty} \varphi I_{j} h(i) d i}_{\text {Expected gain from } G V C}$,

where the first two terms in (A3) are similar to those in equation (A1) and the last term represents the expected benefit from GVC. It is easy to prove that the three terms are strictly increasing with $I_{j}$, which means that the equilibrium level of $\tilde{I}_{G V C}$ is thus unique and such that $V_{G V C}\left(\tilde{I}_{G V C}\right)=s$. Integrating the first and last term of $V_{G V C}\left(\tilde{I}_{G V C}\right)$ (the second being null) leads to the following:

$V_{G V C}\left(\tilde{I}_{G V C}\right)=\int_{o}^{\tilde{I}_{G V C}} \tilde{I}_{G V C} h(i) d i+\pi \int_{\tilde{I}_{G V C}}^{+\infty} \varphi \tilde{I}_{G V C} h(i) d i=\tilde{I}_{G V C}\left(G\left(\tilde{I}_{G V C}\right)^{N-1}+\pi \varphi\left(1-G\left(\tilde{I}_{G V C}\right)^{N-1}\right)\right)$.

The equilibrium level of $\tilde{I}_{G V C}$ is thus obtained by equating (A4) to $s$. It is easy to prove that $\pi \varphi=0 \rightarrow$ $\tilde{I}_{G V C}=\tilde{I}$, and that $\tilde{I}_{G V C}$ is decreasing in $\pi \varphi$. These two results, combined, prove that: $\tilde{I}_{G V C}<\tilde{I}$.

Finally, in presence of a GVC, equation (7) becomes as follows:

$$
\Pi_{V C}^{\text {With } G V C}=\underbrace{E\left[I_{1}-I_{2}\right]}_{\begin{array}{c}
\text { Profit if } \\
n>1
\end{array}} \underbrace{\left(1-G\left(\tilde{I}_{G V C}\right)^{N}-G\left(\tilde{I}_{G V C}\right)^{N-1}\left(1-G\left(\tilde{I}_{G V C}\right)^{N}\right)\right)}_{\begin{array}{c}
\text { Probability that } \\
n>1
\end{array}}>\Pi_{V C}^{\text {Without GVC }} .
$$

Where the first term of (A5) is the same as in Equation 7 (because it only depends on $N$ and on the distributional properties of $I$ ), and the second term is greater than in equation 7 because $\tilde{I}_{G V C}<\tilde{I}$. 


\section{Associate Editor's comments:}

I am happy with the revised version of the paper. I have two remaining comments that you might consider. The decision with regard to both of them is ultimately yours.

First, I still find Section 2.1 (i.e. US vs European VC markets) unnecessary. Please consider removing this section.

Second, the literature review on Governmental VCs is largely based on your own papers. Please consider a broader perspective.

\section{Our Reply}

We agree with both the two remaining comments. We have modified the paper as follows:

a) Section 2.1 has been deleted

b) the literature review on Governmental VC has been enriched by other contributions rather than solely ours, which resulted in a broader perspective on the topic.

We are extremely grateful to the associate editor and the two referees for their invaluable comments.

Best,

The authors 